\title{
AFROCENTRICIDADE E INTERCULTURALIDADE CRÍTICA NA EDUCAÇÃO: reinventar a escola a partir da diferença
}

\author{
Jonathas Vilas Boas de Sant'Ana' \\ João Henrique Suanno² \\ Raimundo Márcio Mota de Castro 3
}

\section{RESUMO}

As diferenças culturais existentes na sociedade brasileira pressionam e penetram como nunca antes a educação escolar. Todavia, a escola permanece assentada no paradigma científico newtoniano-cartesiano, erigido na modernidade ocidental como parte constitutiva da estrutura de dominação montada desde 1500, a colonialidade do poder. Como via de rompimento com esta realidade é necessário fortalecer a interculturalidade desde epistemologias subalternizadas que ajudem a proceder uma descolonização epistemológica. Neste sentido, o objetivo deste artigo é apontar a potencialidade do paradigma da afrocentricidade para a construção de uma educação intercultural crítica que leve à reinvenção da educação escolar. Interculturalizar a educação implica em reinventar a escola em suas diversas dimensões, incorporando a diferença como constitutiva e não como aditiva. Consiste na abertura epistemológica da educação para a diferença. A partir daí propõe-se que o paradigma da afrocentricidade, enquanto epistemologia subalternizada permite repensar a educação escolar em diversos sentidos. Considerar referenciais de pensamento africano na educação é um processo de abertura intercultural, de descolonização epistemológica, de contrariedade à colonialidade do poder. Ao mesmo tempo é a proposição de outras formas de relação com as diferenças culturais.

Palavras-chave: Educação escolar. Diferenças culturais. Afrocentricidade.

\footnotetext{
1 Mestre em Educação, Linguagem e Tecnologias pela Universidade Estadual de Goiás. Graduado em Pedagogia pela Universidade Estadual de Goiás. Participa do Grupo de Pesquisa em Rede Internacional Investigando Escolas Criativas e Inovadoras. Membro da Rede Internacional de Escolas Criativas - RIEC Brasil. Professor da educação básica na Secretaria de Estado de Educação do Distrito Federal. E-mail: jonathasvilas@hotmail.com

${ }^{2}$ Pós-Doutorado em Educação - 2014 - Universidade de Barcelona/ES. Doutor em Educação - 2013 - Universidade Católica de Brasília/DF. Professor do quadro permanente do Programa de Pós-Graduação Interdisciplinar em Educação, Linguagem e Tecnologias - IELT, da Universidade Estadual de Goiás. Professor titular efetivo e dedicação exclusiva da Universidade Estadual de Goiás - UEG. Membro da Rede Internacional de Escolas Criativas RIEC Brasil. Líder do Grupo de Pesquisa em Rede Internacional Investigando Escolas Criativas e Inovadoras. E-mail: suanno@uol.com.br

3 Pós-doutorado em Educação Escolar e Religião (PUCPR). Doutor em Educação (PUCGoiás). Mestre em Educação (UNIUBE/MG). É professor titular de Educação, na Universidade Estadual de Goiás, realizando suas atividades docentes e de pesquisa no Campus Senador Canedo e no Programa de Pós-graduação Stricto Senso Interdisciplinar em Educação Linguagem e Tecnologias (PPG-IELT). E-mail: prof.marcas.posgrad@gmail.com
}

Revista Exitus, Santarém/PA, Vol. 9, № 1, p. 426 - 454, JAN/MAR 2019. 


\title{
AFROCENTRICITY AND CRITICAL INTERCULTURALITY IN EDUCATION: reinventing
}

\author{
school based on difference
}

\begin{abstract}
The cultural differences existing in Brazilian society push and penetrate school education as never before. However, the school remains rooted in the newtoniancartesian scientific paradigm built in western modernity as a constituent part of the structure of domination erected since 1500, the coloniality of power. As a way of breaking with this reality, it is necessary to strengthen interculturality considering subalternized epistemologies that help to proceed an epistemological decolonization. In this sense, the objective of this article is to point out the potential of the afrocentricity paradigm for the construction of a critical intercultural education that leads to the reinvention of school education. Intercultural education implies reinventing the school in its various dimensions, incorporating difference as constitutive and not as additive. It consists of the epistemological opening of education to difference. From there, it is proposed that the paradigm of Afrocentricity as a subalternized epistemology allows us to rethink school education in different senses. To consider references of African thinking in education is a process of intercultural openness, of epistemological decolonization, of contrariness to the coloniality of power. At the same time it is the proposition of other forms of relation with the cultural differences.
\end{abstract}

Keywords: School Education. Cultural differences. Afrocentricity.

\section{AFROCENTRICIDAD E INTERCULTURALIDAD CRÍTICA EN LA EDUCACIÓN:}

\author{
reinventar la escuela a partir de la diferencia
}

\section{RESUMEN}

Las diferencias culturales existentes en la sociedad brasileña presionan y penetran como nunca antes la educación escolar. Sin embargo, la escuela permanece asentada en el paradigma científico newtoniano-cartesiano erigido en la modernidad occidental como parte constitutiva de la estructura de dominación montada desde 1500, la colonialidad del poder. Como vía de rompimiento con esta realidad es necesario fortalecer la interculturalidad considerando epistemologías subalternas que ayuden a proceder a una descolonización epistemológica. En este sentido, el objetivo de este artículo es apuntar la potencialidad del paradigma de la afrocentricidad para la construcción de una educación intercultural crítica que lleve a la reinvención de la educación escolar. Interculturalizar la educación implica reinventar la escuela en sus diversas dimensiones, incorporando la diferencia como constitutiva y no como aditiva. Consiste en la apertura epistemológica de la educación hacia la diferencia. A partir de ahí se propone que el paradigma de la afrocentricidad como epistemología subalterna permita repensar la educación escolar en diversos sentidos. Considerar referencias de pensamiento africano en la educación es un proceso de apertura intercultural, de descolonización 
epistemológica, de contrariedad a la colonialidad del poder. Al mismo tiempo es la proposición de otras formas de relación con las diferencias culturales.

Palabras clave: Educación escolar. Diferencias culturales. Afrocentricidad.

\section{INTRODUÇÃO}

A educação tem sido chamada a refletir sobre a diversidade cultural existente na sociedade e cada vez mais presente no espaço escolar. Na maior parte dos 500 anos de história da educação no Brasil o acesso à escolarização era restrito à elite branca da população, excluídos sistematicamente negros e índios (SANT'ANA; LOPES, 2015). Porém, as últimas décadas são marcadas pelo aumento do número de matrículas nas escolas do país. Atualmente, beiramos a universalização do Ensino Fundamental com cerca de $97,9 \%$ da população de sete a catorze anos matriculada em instituições públicas ou privadas 4 .

Com a elevação da quantidade de alunos a entrar nas escolas, aumentaram também as diferenças culturais presentes nas salas de aula, não apenas no Brasil, mas em todo o mundo. Embora ainda existam desigualdades estruturais referentes ao acesso à escolarização, durante o século XX esta instituição se expande em todo o mundo, tornando-se bastante heterogênea no que diz respeito ao alunado (CANÁRIO, 2008). Especialmente nos corredores das escolas públicas brasileiras há múltiplas diferenças culturais, religiosas, étnico-raciais, econômicas, físicas, estéticas, cognitivas, familiares etc. entre os estudantes.

A diversidade existente na sociedade penetra como nunca antes os muros das instituições escolares. Mas isto não tem correspondido a uma abertura da escola para as diferenças culturais, individuais e, sobretudo, epistemológicas. A convivência entre/com os - e a abertura aos - diferentes na escola brasileira ainda é um desafio, pois esta instituição, tal como tem-se atualmente, é essencialmente e historicamente excludente.

\footnotetext{
4 Estatística da Meta 2 do diagnóstico do Plano Nacional de Educação. Disponível em: <http://simec.mec.gov.br/pde/graficopne.php> Acesso em 25 de janeiro de 2018.
} 
Paralelamente, sujeitos sociais diversos deixam de aceitar posições historicamente determinadas e reivindicam novos espaços e direitos com posições políticas na busca de legitimação e reconhecimento. Torna-se "indispensável imaginar outras possibilidades de ser, de agir, de dialogar, de viver" (MOREIRA; SILVA JÚNIOR, 2016, p. 47) diante de tal efervescência que fundamentalmente põe em questão o projeto da modernidade.

Neste contexto, o objetivo do presente trabalho é apontar a potencialidade do paradigma da afrocentricidade para a construção de uma educação intercultural crítica que leve à reinvenção da educação escolar. Trata-se de uma pesquisa teórica, no sentido de tentar "compreender ou proporcionar um espaço para discussão de um tema ou uma questão intrigante da realidade" (VILAÇA, 2010, p. 64). Para Demo (1985, p. 23) a pesquisa teórica "monta e desvenda quadros teóricos de referência [...] que são contextos essenciais para o pesquisador movimentarse" em constante diálogo com a realidade circundante.

O esforço do presente artigo se configura na direção de articular referenciais teóricos que possibilitem visualizar a realidade educacional, a partir de uma nova perspectiva. Destacamos que o "sujeito pesquisador não é um relator passivo e sim um agente ativo na construção do mundo" (BORTONI-RICARDO 2008, p. 59). Assim, toda a discussão empreendida no texto corresponde a um olhar sobre a realidade e não a uma verdade acabada.

Na primeira parte do texto analisaremos o caráter excludente da educação escolar no Brasil, fundada na ciência moderna ocidental derivada da colonialidade do poder. A partir daí apontaremos a interculturalidade crítica como perspectiva potente de superação desta condição. Em seguida, apresentaremos a afrocentricidade e algumas de suas possíveis contribuições para o fortalecimento de uma educação intercultural crítica. Por fim, reforçaremos a urgência de reinventar a escola com base na discussão precedente. 


\section{ESCOLA CONTEMPORÂNEA E COLONIALIDADE DO PODER}

Excluir e inferiorizar negros, mulheres, crianças, indígenas, homossexuais, não católicos e não cristãos em geral, pobres e deficientes físicos e mentais não é característica pontual e supérflua da escolarização ocidental. Considerar a "diferença" como "inferioridade" não é um capítulo superado na história do Ocidente, nem uma problemática "atual", mas sim uma das principais marcas de um enredo histórico reatualizado e ressignificado constantemente (QUIJANO, 1992).

De acordo com Moraes (2012), a escola ocidental contemporânea está assentada no paradigma moderno newtoniano-cartesiano que concebe a realidade a partir do determinismo, do mecanicismo, da objetividade e da fragmentação. Para enquadrar o mundo dentro de leis matemáticas, este pensamento estabelece a natureza e o "outro" nãoocidental como objetos a serem dissecados e classificados hierarquicamente.

O modo de conhecer daí nascente, produz ignorâncias globais e ações mutilantes presas ao reducionismo, ao binarismo de certo e errado, à linearidade causal e ao maniqueísmo que separa o mundo entre bem e mal, diz Morin (2015). A dilacerada condição da humanidade planetária recortada em guetos nacionalistas e étnicos odiosos em relação aos grupos que lhe são externos é resultante deste tipo de pensamento fragmentário que é ainda imperante.

É indissociável a relação unidade/diversidade: "o tesouro da unidade humana é a diversidade humana, o tesouro da diversidade humana é a unidade humana" (MORIN, 2015, p. 57). Entretanto, a civilização ocidental geralmente tem ignorado este princípio ao expandir sua cultura como superior, pautando-se pela hegemonia do lucro, pela redução da política à economia, pela limitação do conhecimento ao cálculo, pelo domínio da racionalização sobre uma racionalidade aberta.

Esta concepção dominante e dominadora foi construída no contexto da modernidade para responder aos objetivos de expansão do ocidente. Suas influências na educação atual são graves, produzem uma escola 
morta, voltada para o passado e baseada num sistema de referências que prevê a uniformização, o silenciamento, a repetição, a fragmentação, o abafamento da criatividade, bem como a desconsideração da diversidade sociocultural dos estudantes (MORAES, 2012).

Mais do que isto, o sistema escolar, como instituição destinada à socialização do conhecimento produzido pela ciência ocidental, tem em si uma cor de pele cultural (SODRÉ, 2012), validada como superior. O modelo humano da modernidade ocidental baseia a escola, fazendo imperar basilarmente, nesta instituição um racismo doutrinário em que o branco europeu é considerado equivalente ao valor universal e superior de humanidade. Assim, "Negro, índio, mestiço e mulato seriam, por conseguinte, formas incompletas do 'homem pleno', modelado pelo europeu" (SODRÉ, 2012, p. 50).

Nesta perspectiva, compreende-se que no Brasil ocorreu uma exclusão histórica de negros e indígenas quanto ao acesso à escola e quanto à influência sobre a concepção de educação e sobre os conteúdos curriculares, dentre outras dimensões do sistema educacional. Sant'Ana e Lopes $(2015$, p. 16) destacam:

Por ter como base um padrão único de pensamento, uma única mentalidade herdeira da colonização, a escola, ao se abrir obrigatoriamente para a universalidade dos sujeitos com suas diversidades, choca-se com a pluralidade que estes trazem contra a sua unicidade estrutural. Daí que surjam os conflitos e resultados negativos do sistema de ensino contemporâneo, que tem se tornado incapaz de atender à demanda formativa atual.

Em outras palavras, um dos eixos centrais da problemática educacional na atualidade é a homogeneidade cultural dos processos educativos diante de um público que é cada vez mais diversificado. O problema não são as diferenças dos alunos, como se fossem défices, mas sim a estrutura arcaica da escola baseada numa hierarquização simbólica, numa representação social em que se constrói o "diferente" com relação ao padrão ocidental como "deficiente" ou "desviante" que deve ser corrigido ou convertido (CANEN, 2001; CANDAU, 2012). 
Tal classificação simbólica pode ser compreendida a partir do que em alguns "círculos de estudos pós-coloniais costuma-se chamar de colonialidade, ou seja, a dominação de caráter cultural, que nega igualdade ao diferente" (SODRÉ, 2012, p. 42, grifos do autor).

O termo colonialidade do poder é cunhado por Quijano (1992), que compreende o poder global atualmente em vigor como tendo início com as conquistas coloniais europeias sobre o território hoje chamado de América Latina, mas que se expandiu para outros locais, no processo de colonização. Uma estrutura hierárquica de poder cultural e simbólico foi fundada junto ao colonialismo de 1500, endossando o eurocentrismo já anteriormente existente. Chamada de colonialidade, esta dominação está para além das relações exploratórias e materiais concretas, é mais profunda que o colonialismo formal e político. Foi esta "estrutura colonial de poder [que] produziu as discriminações sociais que posteriormente foram codificadas como 'raciais', étnicas, 'antropológicas ou 'nacionais'" (QUIJANO, 1992, p. 12, tradução nossa). Estas categorias classificatórias subjacentes ao colonialismo e perpetuadas para além dele foram assumidas como sendo retrato de uma realidade "natural", incidindo nas linhas globais de desenvolvimento e exploração atuais a nível internacional e local.

Em outras palavras, a colonialidade do poder é o modo geral de dominação no mundo atual, operando com base no colonialismo, mas superando-o na medida em que a hierarquização e a exploração do mundo passam a ter uma dimensão cultural.

Para Grosfoguel (2009), a colonialidade do poder envolve uma arquitetura global de dominação a partir de uma Matriz de Poder ocidental que produz hierarquias múltiplas engendradas numa padronização centralizada no modelo humano europeu, impondo a classificação social no que concerne à dimensão sexual, epidérmica, política, religiosa, econômica, geográfica, étnico-racial e epistemológica. Esta estrutura é forjada pela colonialidade do poder. Perceber a experiência da colonialidade ajuda a entender que a espoliação econômica é mais grave contra africanos, latino- 
americanos e seus respectivos descendentes, porque a dimensão racial é o ponto central da dominação capitalista ocidental.

De acordo com Quijano (1992), a colonialidade do poder é constitutiva da racionalidade moderna ocidental. Os modos não-ocidentais de conhecer e produzir conhecimentos, imagens e símbolos foram reprimidos pelo paradigma europeu que ao mesmo tempo se impôs como superior e objeto de desejo por dar acesso ao poder. Com a fundação do cartesianismo, é o homem ocidental que passa a ser considerado como possuidor do ego cogito enquanto potência de pensar e produzir conhecimento válido (GROSFOGUEL, 2009).

Fora do cogito ocidental não há produção científica; há apenas uma zona colonial a ser explorada pelas conquistas modernas. Tal é a lógica do "paradigma europeu de conhecimento racional, [que] não somente foi elaborado no contexto de, senão como parte de uma estrutura de poder que implicava a dominação colonial europeia sobre o resto do mundo" (QUIJANO, 1992, p. 16, tradução nossa). Logo, a ciência da modernidade ocidental não é alheia à colonialidade do poder, mas eixo estruturante desta. Na escola fundada nesta ciência a inferiorização das diferenças não é um desvio de percurso e sim a rota original.

Santos (2009) afirma que a hegemonia científica derivada do pensamento moderno ocidental funda linhas divisórias globais quanto à capacidade epistemológica humana: de um lado o colonizador, o homem ocidental, capaz de produzir conhecimento universalmente válido; de outro os colonizados, os indígenas, latino-americanos, africanos, asiáticos, capazes de criar apenas saberes incompreensíveis, mitológicos e mágicos. Para romper com esta hierarquização epistêmica o autor propõe uma ecologia de saberes como descolonização epistemológica e aceitação da pluralidade e das diferenças dos conhecimentos produzidos em qualquer parte do globo. Em lugar de fundar uma epistemologia universal, a ecologia de saberes abre espaço para o diálogo e o intercâmbio entre diferentes sujeitos e suas produções cognitivas. 
Nesta perspectiva dialógica é possível constituir o que Santos (1997) chama de hermenêutica diatópica, isto é, um diálogo intercultural como troca entre possibilidades e limitações de diferentes culturas. A hermenêutica diatópica não produz uma síntese cultural, mas amplia ao máximo a "consciência de incompletude mútua através de um diálogo que se desenrola, por assim dizer, com um pé numa cultura e outro, noutra" (SANTOS, 1997, p. 116).

É preciso superar as condições negativas deixadas pelo pensamento moderno por meio de uma abertura paradigmática que considere as contribuições das diversas culturas para gerar uma nova civilização sustentada em valores humanistas, democráticos, ambientalmente sustentáveis e comunitários, como defende Morin (2015). A transição do paradigma newtoniano-cartesiano para a emergência de outras epistemologias é fundamental, se almejamos a sobrevivência da humanidade em condições de convivência entre as diferenças.

Como constituição de uma dialógica contra hegemônica, a ecologia de saberes e a hermenêutica diatópica fortalecem a derribada da colonialidade do poder na medida em que se movimentam rumo a uma abertura paradigmática e propõem uma perspectiva de (inter)ação e colaboração horizontal que pode ser pensada também na educação. Aliás, para Quijano (1992, p. 20) é necessário que ocorra a

[...] liberação das relações interculturais da prisão da colonialidade [que] entranha também a liberdade de todas as pessoas, de optar individual ou coletivamente em tais relações; uma liberdade de opção entre as diversas opções culturais. E, sobretudo, a liberdade para produzir, criticar e mudar e intercambiar. É parte, enfim, do processo de liberação social de todo poder organizado como desigualdade, como discriminação, como exploração, como dominação (tradução nossa).

Compreende-se que as hierarquias entre culturas, conhecimentos e modos de produção de conhecimentos montadas a partir da colonialidade do poder podem ser rompidas a partir do estabelecimento de uma interculturalidade que promova intercâmbio, produção, crítica e mudanças (QUIJANO, 1992; SANTOS, 1997). Ao mesmo tempo, uma abertura radical às 
produções epistemológicas "de lugares étnico-raciais subalternos pode contribuir em muito para uma teoria crítica descolonial radical" (GROSFOGUEL, 2009, p. 385).

Neste sentido, a interculturalidade crítica pode contribuir para repensar a educação no contexto contemporâneo ao operar uma abertura fundamental a epistemologias subalternizadas pela racionalidade ocidental. Deste modo se tornam possiveis outras formas de relação entre escola e diferenças culturais, aproveitando as brechas que vêm sendo abertas pelas teorizações e legislações das três últimas décadas no Brasil (BONIN; RIPOLL; GUIZZO, 2016).

\section{INTERCULTURALIZAR, REINVENTAR A ESCOLA}

Frente à heterogeneidade cultural do mundo tem-se ainda um cenário educacional moderno, colonialista, ocidental, tecnológico, branco, masculino, homogeneizante, normatizador. Urge "ressignificar o universalismo em face da pluralidade cultural, de forma a contribuir para práticas educacionais multiculturais eticamente fundamentadas" (OLIVEIRA, CANEN; FRANCO, 2000, p. 114). Ao mesmo tempo, as pressões derivadas dos movimentos sociais, do desenvolvimento de políticas curriculares voltadas para a diversidade, das políticas afirmativas para minorias étnicas, da inclusão de pessoas com deficiência física e mental e da defesa da diversidade de gênero propõem uma "leitura positiva da pluralidade social e cultural [...] uma proposta de 'educação para a alteridade'"' (FLEURI, 2003, p. 17).

Nesta direção, segundo Fleuri (2006), emerge a polissemia terminológica em torno da interculturalidade e do multiculturalismo. Em linhas gerais, autores como Canen; Oliveira e Franco (2000), Canen (2001), Fleuri (2003; 2006) e Candau (2012; 2014), destacam que o termo multiculturalismo pode representar diferentes posições no contexto da educação: a assimilacionista, em que se afirma a multiculturalidade existente na sociedade, com a pretensão de integrar as diferenças sob a hegemonia de uma cultura, sem colocar em questão o caráter monocultural 
da escola; a diferencialista, que enfatiza o reconhecimento e a expressão das diferenças, assumindo uma visão essencialista sobre as culturas e as identidades culturais; e a interativa, que acentua as relações entre as diferenças e questiona as assimetrias de poder existentes na sociedade, bem como, o caráter monocultural da escolarização.

Para, além disto, Silva (2003) pontua que, em geral, o multiculturalismo está ligado à afirmação da existência de diferenças culturais, enquanto a interculturalidade prevê a intencionalidade de colocar as culturas em relação, especialmente, no contexto da América Latina. Na esteira de Fleuri (2003; 2006) e Candau (2010; 2012; 2016), assumimos a perspectiva intercultural em seu sentido crítico. Desta forma, direcionamos o olhar para a construção de sociedades democráticas e inclusivas, em que as diferenças sejam concebidas como produções híbridas, fluidas, polissêmicas, constituídas nas relações de interação, inclusive no âmbito escolar. A interculturalidade crítica também aponta para a transformação social na medida em que problematiza as relações assimétricas de poder e propõe a aceitação basilar às diferenças e ao diálogo entre estas.

Alinhada à proposição da descolonização em relação à colonialidade de poder, a interculturalidade crítica é discutida por Walsh (2007; 2010) como emergente dos movimentos sociais indígenas equatorianos, nos anos de 1990, exigindo uma forma de governo atenta à sua cultura. Como processo por construir, a interculturalidade crítica,

[...] não é simplesmente reconhecer, tolerar ou incorporar o diferente dentro da matriz e das estruturas estabelecidas. Pelo contrário, é implodir - desde a diferença - as estruturas coloniais do poder como desafio, proposta, processo e projeto; é reconceitualizar e refundar as estruturas sociais, epistêmicas e de existências que põem em cena e em relação equitativa lógicas, práticas e modos culturais diversos de pensar, atuar e viver. Por isto, o foco problemático da interculturalidade não reside somente nas populações indígenas e afrodescendentes, senão em todos os setores da sociedade, com a inclusão dos brancos-mestiços ocidentalizados (WALSH, 2010, p. 79, tradução nossa).

Nota-se que a interculturalidade crítica parte da diferença para questionar o sistema social fundado na colonialidade e propor uma outra 
lógica, na qual, a diferença seja a própria base de compreensão e estruturação da realidade. Assim, qualquer que seja a diferença, racial, de gênero, religiosa, enfim, cultural, a interculturalidade crítica é processo de transformação, desde esta diferença. Não é uma inclusão superficial da diferença, um discurso sobre a diferença, mas a transformação dos fundamentos sociais e institucionais, tradicionalmente fixos, para que sejam construídos a partir da pluralidade das diferenças culturais. Por isto mesmo, não é a negação da produção cultural ocidental, mas sua inclusão numa perspectiva de pluralidade e abertura.

A interculturalidade crítica é uma abertura epistêmica às diferenças, ao mesmo tempo em que é a proposição de mudança social, a partir das diferenças. Requer a construção de outro conhecimento, de outra prática política, de um poder social outro, de uma sociedade outra; "uma forma outra de pensamento relacionada com e contra a modernidade/colonialidade" (WALSH, 2007, p. 47, tradução nossa).

Trata-se de uma autêntica busca pela emancipação quanto à colonialidade do poder com suas múltiplas estruturas hierárquicas. Pode ser entendida, assim, como uma via de construção da inteligibilidade entre a mestiçagem cultural e de afirmação do princípio da unidade/diversidade humana necessário à sobrevivência planetária (MORIN, 2015).

Assim, uma educação intercultural crítica, pressupõe aceitar as diferenças culturais como riqueza, desconstruir preconceitos e discriminações presentes na sociedade, questionar o etnocentrismo que marca a escola e as políticas educativas e curriculares, articular o direito à diferença e à igualdade, resgatar processos de construção das identidades culturais brasileiras, dialogar constantemente com os diferentes, reconstruir a dinâmica educacional no que se refere a todas as dimensões do processo educativo (seleção curricular, organização espacial e temporal, linguagens, práticas didáticas etc.) e favorecer processos de empoderamento individual e coletivo de pessoas pertencentes a culturas negadas (CANDAU, 2012; 2016). 
Nesta perspectiva, urge reinventar a escola, repensar a cultura escolar (formas, ritos e aspectos didático-pedagógicos) e a cultura da escola (currículo, conteúdos e conhecimentos socializados), questionando o papel da instituição agora e no futuro. "É a própria concepção da escola, suas funções e suas relações com a sociedade, o conhecimento e a construção de identidades pessoais, sociais e culturais que está em jogo" (CANDAU, 2010, p. 68).

Interculturalizar criticamente a educação é valorizar a mestiçagem, reconhecer as relações de poder na dinâmica sociocultural, questionar continuamente a racialização, a subalternização e a inferiorização construídas a partir de padrões ocidentais de poder, desvelar o daltonismo cultural da escolarização, evidenciar a ancoragem histórico-social dos conteúdos, promover o encontro sistemático com o outro, conceber a escola como espaço de crítica e produção cultural mediada por diversas mídias e linguagens, prezar por uma ética construída no diálogo a posteriori e considerar como uma das principais finalidades da educação a alteridade e a "irrupção do outro" (OLIVEIRA; CANEN; FRANCO, 2000; FLEURI, 2003; 2006; WALSH, 2007; 2010; CANDAU, 2010; 2012; 2014; 2016).

Para que a interculturalidade crítica alcance tal profundidade na educação torna-se necessária a descolonização epistemológica, a abertura a formas de pensamento distintas da racionalidade moderna ocidental, para que a diferença seja fundamentalmente constitutiva e não superficialmente aditiva. Neste sentido, apresentaremos o paradigma da afrocentricidade e algumas de suas possíveis contribuições para interculturalizar, reinventar a educação escolar.

\section{O PARADIGMA DA AFROCENTRICIDADE}

Apontamos o paradigma da afrocentricidade, como epistemologia potente para transitar na direção de uma abertura paradigmática, em relação ao pensamento moderno (MORIN, 2015) e fortalecer a interculturalidade crítica na educação. Faremos apenas um movimento 
inicial no sentido de apresentar a afrocentricidade, sem esgotar as possibilidades de discussão.

O paradigma afrocentrado de pensamento surge como resposta à pretensão exclusivista dos Estados Unidos da América e da Europa em escrever a história universal, a partir de sua ótica etnocêntrica e do poder intelectual construído como superior ao restante da humanidade. Contra esta dominação, o termo "afrocentricidade" foi cunhado por Molefi Asante (2009) no final do século XX como paradigma de trabalho acadêmico.

Mas como orientação de pensamento e investigação, a abordagem afrocentrada é mais antiga, erigida pelo menos desde a revolta despertada pela cerimônia do voudou em 1791 no Haiti. Finch III e Nascimento (2009, p. 38) atestam:

\begin{abstract}
A tradição de pensamento afrocentrado desenvolvida no contexto intelectual do Ocidente consiste, com efeito, num ato de resistência. Ligada intimamente ao pan-africanismo, ela se constitui na tessitura das ligações entre continente e diáspora ao protagonizar esta resistência.
\end{abstract}

Assim, a afrocentricidade é gestada ainda no contexto escravagista do século XVIII, tendo espaço no projeto político pan-africanista do século XIX (NOGUERA, 2010), e desponta de modo mais sistemático e contundente no século XX. Descontentes com a esquerda marxista que relegava a segundo plano os problemas da segregação racial, ativistas como William Edward Burghardt Du Bois, Richard Wright, George Padmore, Marcus Garvey e Abdias do Nascimento passam a construir novas teorizações para a problemática racial em seus respectivos contextos, ensaiando o que posteriormente viria a ser chamado por outros de afrocentricidade.

Porém, é a produção intelectual de Cheikh Anta Diop sobre a história africana que impulsiona a formalização da abordagem afrocentrada. Segundo Finch III (2009a), Diop chegou a algumas conclusões em seus estudos: a humanidade começou na África; o Antigo Egito foi uma civilização negro-africana; a ciência, a medicina, a filosofia, a arquitetura, a engenharia e a arte civilizada surgiram primeiro no vale do rio Nilo; os reinos pré-coloniais da África Ocidental desenvolveram governos e organizações 
sociais altamente sofisticadas; há uma unidade cultural entre toda a África Negra.

Deste modo, Diop reconstruiu o passado africano e recolocou a África como local que "trouxera à luz a humanidade e a civilização, imprimindo influência sobre os assuntos do mundo até o tempo da Renascença" (FINCH III; NASCIMENTO, 2009, p. 64-65). Tradicionalmente o Egito é travestido de branco nas produções científicas e imagéticas ocidentais, negando as raízes negro-africanas do conhecimento, posteriormente, desenvolvido como produto único da Europa e difundido sob a lógica de dominação. Diop coloca em questão toda esta racialização e falsificação europeia sobre a África, que a considera inferior e incapaz de relevante criação cultural, política, econômica e científica. O autor inaugura a produção de conhecimento a partir de um lugar específico, a África, e com um olhar afrocentrado (FINCH III, 2009a).

A afrocentricidade é uma proposta epistemológica que parte do lugar africano. Diante da marginalização imposta pelo eurocentrismo

[...] a afrocentricidade é um tipo de pensamento, prática e perspectiva que percebe os africanos como sujeitos e agentes de fenômenos atuando sobre sua própria imagem cultural e de acordo com seus próprios interesses humanos (ASANTE, 2009, p. 93, grifos do autor).

Mazama (2009, p. 111) ressalta que a afrocentricidade afirma a operação dos africanos como agentes autoconscientes insatisfeitos "em ser definidos e manipulados por fora". Finch III (2009b, p. 167) define afrocentricidade como "uma escola de pensamento que coloca a África no centro de todos os estudos que se relacionam com esse continente e com os povos de descendência africana" (grifos do autor). Para Rabaka (2009), trata-se de uma orientação metodológica para análise da história e da cultura africana e mundiail, como forma de crítica e de corretivo diante da hegemonia branca global.

Diante destas definições convergentes, podemos afirmar a afrocentricidade como um paradigma epistemológico e metodológico, que orienta a construção do conhecimento numa perspectiva propriamente 
africana, originada a partir da consciência sobre a experiência comum de africanos e afrodescendentes, diante da imposição mundial da supremacia branca. Nesta direção, a afrocentricidade é marcada pela crítica contra hegemônica e pela afirmação de outras possibilidades de pensamento e organização social em que a solidariedade e a coletividade sejam princípios norteadores contra todas as formas de opressão da liberdade humana.

Para Asante (2009, p. 94), a afrocentricidade busca construir nas pessoas a agência enquanto "capacidade de dispor dos recursos psicológicos e culturais necessários para o avanço da liberdade humana". Neste sentido, é um paradigma que desafia a racionalidade eurocêntrica responsável pelo desprezo e invisibilização dos africanos. A experiência africana dos povos africanos é o princípio que organiza a percepção da realidade a partir desta perspectiva (MAZAMA, 2009; NOGUERA, 2010). Asante $(2009$, p. 94) destaca a preocupação central com a conscientização política de um povo mantido "à margem da educação, da arte, da ciência, da economia, da comunicação e da tecnologia tal como definidas pelos eurocêntricos".

O paradigma da afrocentricidade parte da afirmação do lugar enquanto consciência histórica e política, da opressão da supremacia branca sobre outros povos, especialmente os africanos. Ser afrocentrista não significa ser negro (como essencialismo biológico ou "racial"), ter nascido na África ou defender a afrocentricidade como perspectiva única de explicação da realidade. Não é feita uma inversão da hierarquia eurocêntrica ou a desconsideração do pensamento e da cultura dos europeus. É sim, a destruição da hierarquia e da afirmação de igualdade humana de todos os povos e culturas (ASANTE, 2009; RABAKA, 2009; NOGUERA, 2010).

Afrocentricidade não representa um lugar geográfico, embora parta da experiência continental e diaspórica dos africanos; a ideia de centro contida no termo não implica em localização espacial, e sim, em uma posição mental, política e epistemológica de resistência à dominação cultural europeia empreendida por mais de 500 anos. O pensamento 
posicionado nesta perspectiva se refere a uma abertura paradigmática geral por meio da contestação de todas as formas de dominação ocidentais. Concretiza-se também, na preocupação com uma alteridade específica, e assim, avança para além dos discursos abstratos sobre a necessidade de respeito às diferenças.

Ao oportunizar a crítica de sujeitos concretos, situados no tempo e no espaço da hierarquização ocidental moderna, a afrocentricidade descentraliza hegemonias fixas e abre rupturas que contribuem na construção de "fechamentos contingentes", para usar as palavras de Moreira e Silva Junior (2016, p. 51). Para os autores, mesmo considerando as perspectivas pós-estruturalistas que rejeitam a ideia de essencialismo identitário ou cultural e, desta forma, aceitando que as diferenças são produções ficcionais circunscritas no âmbito do discurso, é possível pensar em fechamentos transitórios de identidades, comumente inferiorizadas a fim de possibilitar a ação política referente a sujeitos concretos. É nesta direção que situamos a afrocentricidade como fechamento contingente daqueles que se veem diante da dominação branca.

Assumir a afrocentricidade é "reivindicar o parentesco com a luta e perseguir a ética da justiça contra todas as formas de opressão humana" (ASANTE, 2009, p. 102). Além disto, é interpelar

[...] as dicotomias científicas ocidentais: mente versus corpo; eu versus outro; cientista social como sujeito versus pessoa, lugar ou fenômeno sob investigação "científica" como objeto. Os afrocentristas julgam problemática a "abordagem desinteressada" que pretensamente permite a "objetividade" científica porque não questiona - ou, na linguagem dos afrocentristas, não localiza - as raízes racistas do empreendimento científico ocidental (RABAKA, 2009, p. 135, grifos do autor).

Além disso, contrapondo-se à ciência ocidental, o pensamento afrocentrado é caracterizado por alguns pontos: o interesse pela localização psicológica, cultural, histórica ou individual das pessoas; o compromisso com a descoberta do lugar africano como sujeito; a defesa dos elementos culturais africanos; o compromisso com o refinamento léxico (preocupação 
se a linguagem é baseada numa perspectiva africana); o compromisso com uma nova narrativa da história da África (ASANTE, 2009).

A afrocentricidade reconhece $O$ caráter agressivo da visão antiespiritual e pró-material ocidental que leva o mundo à beira da destruição, por conta do desenvolvimento tecnológico irresponsável, da corrupção alastrada, da violência sistêmica e da matança de pessoas nas guerras. Esta também é uma preocupação de autores como Morin (2015). Logo, "Não podemos entregar a direção filosófica do planeta àqueles cujos padrões de ambição e destruição ameaçam aniquilar-nos. [...] $\mathrm{Na}$ visão afrocêntrica, todo conhecimento deve ser emancipador" (ASANTE, 2009, p. 104). A afrocentricidade é constituída por uma lógica distinta da hierarquização ocidental e valoriza a vida em todas as suas dimensões objetivas e subjetivas. Iguala-se a importância de homens e mulheres na produção do conhecimento, opera-se uma abertura epistêmica, propõe-se uma postura humanista, derruba-se qualquer pretensão de visões monoculturais e totalizadoras e fundamenta-se a construção de um eu coletivo na criação e recriação de abordagens metodológicas críticas para os estudos científicos (ASANTE, 2009; RABAKA, 2009; NOGUERA, 2010).

Mazama (2009, p. 123) salienta alguns princípios metodológicos da afrocentricidade:

[...] toda investigação deve ser determinada pela experiência africana; o espiritual é importante e deve ser colocado no lugar devido; a imersão do sujeito é necessária; o holismo é um imperativo; deve-se confiar na intuição; nem tudo é mensurável porque nem tudo que é importante é material; o conhecimento gerado pela metodologia afrocêntrica deve ser libertador.

Percebe-se, portanto, que o pensamento afrocentrado propõe uma outra forma de compreender a realidade, a sociedade e a produção de conhecimento. Descarta as marcas coloniais e impositivas presentes na racionalidade moderna ocidental. Desdobra-se num diálogo epistemológico que tenha como horizonte o interesse na liberdade e na dignidade da vida em todo o globo, aspectos que entrelaçam afrocentricidade à interculturalidade crítica. 
Da afrocentricidade decorrem algumas implicações para a educação que podem ajudar a pensar a reinvenção escolar no contemporâneo. Finch III e Nascimento (2009) e Mazama (2009) citam Asa Hilliard III, estudioso que se dedicou à explicação da pedagogia do Antigo Egito, propondo uma abordagem afrocentrada para a educação norte-americana. Nesta visão de mundo africano-kemética (do Kemet) a educação teria como objetivo último levar a:

[...] experimentar a unidade com Deus, tornar-se um com Ma'at. Isto seria alcançado mediante a unidade com o grupo e com a natureza, assim como o desenvolvimento da responsabilidade social, do caráter social e do poder espiritual. A iniciação era de primordial importância, mas o processo de ensino e aprendizado era abrangente, interativo e coletivo, tendo lugar num ambiente que refletia e transmitia a cultura integral dos africanos (MAZAMA, 2009, p. 126-127).

Tratava-se, portanto, de uma educação integral, referida não apenas às dimensões intelectuais, técnicas e concretas da formação dos indivíduos. Considerava-se a natureza transcendental do ser humano, um ser existente apenas por meio da conexão com a coletividade e com a natureza. Assim, a educação é alinhada à vida que passa a ser eixo estruturante das práticas pedagógicas e das finalidades maiores da formação do indivíduo. Destacam-se a interação e a coletividade atravessadas em todo o processo educativo, desenvolvido em ambientes conectados à realidade do mundo natural e social.

Além disso, Asante (2009, p. 96) ressalta que a construção de um currículo escolar "deve prestar atenção à localização psicológica e cultural" do público a ser atendido. Os alunos de escolas tradicionalmente ocidentais recebem um sem-fim de imagens negativas sobre a África e sobre os africanos. Mesmo quando os estudantes são africanos e afrodescendentes, o conteúdo escolar os representa como "indefesos, inferiores, não-humanos, de segunda classe, como se não fizessem parte da história humana" (ASANTE, 2009, p. 99).

Assim, crianças e jovens negros e brancos são levados a assumir a perspectiva europeia individualista, materialista e racista. Mazama (2009, p. 
126) apoiada em Mwalimu Shujaa, acentua que as "reformas educacionais não conseguem melhorar essa realidade, pois o que se questiona não é o sistema opressivo, mas sua modalidade de operação". Ou seja, as alterações são superficiais, não atingem a essência colonialista do sistema escolar. Para a autora seria necessária uma revolução educativa, criando escolas afrocêntricas prontas a ajudar os estudantes a conhecerem a si mesmos e aos mecanismos de opressão socialmente instituídos, a fim de se disporem a destruí-los. Alertamos que tal proposta corre o risco de formar guetos educacionais e precisa ser devidamente problematizada, embora traga a importância de ter processos educativos culturalmente relevantes.

O trabalho de Noguera (2010) apresenta ricas possibilidades de pensar o currículo escolar no contexto da Lei 10.639/03 a partir da afrocentricidade. $\mathrm{Na}$ visão do autor, todas as disciplinas escolares podem ser repensadas desde a localização afrocentrada.

Porém, sem negar as contribuições já apontadas, consideramos que o paradigma da afrocentricidade permite pensar em outras questões para além da proposição de escolas afrocêntricas e da renovação curricular. Afinal, o pensamento afrocentrado busca superar "qualquer tipo de fundamentalismo, etnocentrismo ou visão fechada" (NOGUERA, 2010, p. 3) e preocupa-se com o debate e com a pluralidade de abordagens que visem à liberdade humana. Assim, compreendemos que a afrocentricidade se situa numa perspectiva de educação intercultural crítica na medida em que aponta a dialogicidade e a abertura epistemológica como vias de enfrentamento da colonialidade do poder. Neste sentido, apresentaremos possíveis reverberações da afrocentricidade, no âmbito da construção de uma educação intercultural crítica a partir do que vem sendo discutido neste texto.

\section{REINVENTAR A ESCOLA DESDE A AFROCENTRICIDADE}

A interculturalidade crítica preza pela (re)construção de aberturas epistemológicas (WALSH, 2010) alinhadas à proposição de uma ecologia de saberes (SANTOS, 2009) como resposta ao desafio da descolonização frente 
à colonialidade do poder (QUIJANO, 1992; GROSFOGUEL, 2009). Na educação, isto equivale a pensar a escola com base nas diferenças como condição constitutiva, radical, e não apenas superficial.

Neste sentido, consideramos que no nível mais profundo a afrocentricidade (ASANTE, 2009; MAZAMA, 2009; RABAKA, 2009; NOGUERA, 2010) é um paradigma potente para a abertura de brechas basilares no pensamento educacional, levando a reorganizar a cognição, as referências culturais e as práticas pedagógicas da escola a partir da experiência dos africanos e afrodescendentes com suas culturas e formas de pensamento e de construção do conhecimento - uma rachadura epistemológica nas bases da escolarização que atualmente é fundamentada apenas no paradigma newtoniano-cartesiano ocidental (MORAES, 2012).

Propor a abertura dos fundamentos da educação para a afrocentricidade é também contribuir para que a população brasileira se reconheça na produção histórica e cultural do país. Assim, assumimos ser necessário e urgente

Enriquecer o debate intelectual, a produção acadêmica, as práticas pedagógicas e dialogar com toda a sociedade brasileira com 0 firme propósito de estabelecer topologias epistêmicas que reinventem, reconstruam e ressignifiquem os lugares, as narrativas, os saberes e, sobretudo, redefinir os critérios que estabelecem a legitimidade de determinadas práticas e dinâmicas intelectuais como inválidas e outras, válidas. Se as referências africanas ainda estão pouco disponíveis e marginalizadas, um diálogo despido de ideias estereotipadas a respeito da afrocentricidade pode ser muito fértil para colocar pesquisas afrocentristas à serviço de várias estratégias no campo da educação em favor da diversidade étnica e racial (NOGUERA, 2010, p. 14)

É neste sentido que as reflexões feitas no presente trabalho se localizam, como um movimento inicial e necessário para repensar a educação desde a perspectiva afrocêntrica.

Em dimensões menos abstratas, o pensamento afrocentrado coloca para a educação o desafio de formação para a agência como capacidade autônoma psicológica e cultural de promover a liberdade individual e coletiva. Isto se opõe à proposição verticalizada de um currículo prescritivo e centralizador. Ao mesmo tempo, significa abandonar o 
autoritarismo e a imposição ideológica como formas de controle do pensamento dos alunos. Tanto a estrutura organizacional da escola como a docência devem apostar na autogestão do aluno em sua formação, dando espaço para sua criação por meio da proposição de desafios cognitivos e da problematização das assimetrias de poder estabelecidas na sociedade.

A perspectiva de lugar enquanto posição mental, histórica, cultural e psicológica, presente na afrocentricidade, desdobra-se na possibilidade de que cada instituição escolar tenha autonomia para pensar sua própria história, suas condições, seu contexto, seus alunos, seus limites e potencialidades. Com isto, a escola poderá encaminhar sua própria construção (física, organizacional e pedagógica) de forma colaborativa e democrática para fazer frente a seus desafios particulares, enfrentando a massificação e a uniformização da escolarização.

A escola passaria a ter raízes localizadas em seu espaço físico e conceitual, ganhando consistência e potência diante de sua realidade e de sua comunidade. Nesta perspectiva, os territórios que circundam a instituição escolar são concebidos como espaços educativos e são utilizados para criar uma rede de formação das crianças e adolescentes. As práticas educativas empreendidas na escola se conectam à realidade sociocultural dos alunos, dando sentido subjetivo às aprendizagens e promovendo a docência fundada também na perspectiva de lugar.

Considerar a histórica hegemonia branca em nível global e pautar-se pela construção de conhecimentos desde a ótica dos subalternizados, demanda repensar os conteúdos socializados na escola, suas origens e formas de construção, a fim de reconstruir os currículos, integrando conhecimentos produzidos a partir do olhar africano e indígena, por exemplo. Isto é, uma "demarcação afrocentrada na educação começaria relendo os papéis de todas as atrizes e atores na produção dos diversos saberes" (NOGUERA, 2010, p. 4). Mais do que agregar informações sobre culturas e histórias não-ocidentais, urge deixar que estas vozes falem por si mesmas, por meio de suas próprias epistemologias, categorias conceituais e culturas específicas. Neste sentido, a escola estaria aberta não ao 
conhecimento sobre as diferenças, mas sim ao conhecimento produzido a partir das diferenças.

A localização do conhecimento, além de abranger grupos universalmente inferiorizados, alcança a produção cognitiva de cada contexto escolar específico. No Brasil há enorme diversidade de culturas e conhecimentos produzidos do Sul ao Norte. Caberia a cada escola refletir com a comunidade sobre seu contexto próximo para propor a inclusão de conhecimentos e saberes locais no currículo.

Além disto, compreendemos que pensar a educação intercultural crítica, a partir da afrocentricidade, envolve assumir oposição a todas as formas de opressão existentes na sociedade, como a discriminação étnicoracial e de gênero. De tal modo, a escola torna-se espaço de discussão e de ação democrática para o rompimento de tiranias impostas sobre a liberdade humana. Evidencia-se na educação uma postura humanista advinda da visão de mundo afrocentrada, no sentido de valorizar a humanidade enquanto relação entre indivíduos e coletividade.

Também fica saliente a preocupação com a natureza, por meio do contato direto entre as pessoas e o planeta. Se o homem é completo apenas na medida em que está conectado à realidade espiritual e natural, emergem vivências concretas em que se constrói a oportunidade de relacionar-se positivamente com a natureza e com as outras pessoas.

Buscando superar as cisões fundadas pela racionalidade ocidental, a educação intercultural crítica, construída com apoio da afrocentricidade, reaproxima mente e corpo, por meio de uma organização espacial e temporal da escola que respeite a necessidade de movimentação, dinamicidade e interação dos indivíduos. Na perspectiva afrocêntrica, o corpo, com qualquer epiderme, não é concebido como matéria a ser superada pela abstração, mas como parte essencial do desenvolvimento integral do ser humano. Por este motivo, a dimensão biológica do ser, também tem de ser considerada na cognição, implicando em práticas pedagógicas abertas, dinâmicas e multidimensionais que rompam com a 
tradicional divisão de espaço, tempo e agrupamento da escolarização, pensada para disciplinar e não para educar.

Desfaz-se a lógica de oposição presente no paradigma europeu para que o "eu" e o "outro" estejam em constante relação de crescimento e construção dialógica. As identidades culturais são interativas e cambiáveis. Os preconceitos e estereótipos podem ser superados por meio de processos que coloquem as diferenças num plano intercultural. Também são reaproximados o sujeito conhecedor e o objeto de conhecimento, pois, fora desta relação, a produção cognitiva corre o risco de perpetuar as hierarquias estabelecidas na ciência originada junto à colonialidade do poder.

No nível didático, estas considerações impulsionam metodologias integralizadoras e holísticas, que considerem todas as dimensões da existência humana. Assim, rejeitam-se atividades mecânicas, ancoradas na pura memorização, dissociadas da subjetividade e da cultura dos indivíduos e assentadas na uniformização massiva do processo de aprendizagem. Em lugar disto, a afrocentricidade aponta para propostas didáticas vivenciais calcadas na existência concreta dos alunos, em seus contextos socioculturais e no horizonte de libertação humana. Possibilitam-se estratégias diversificadas para o ensino e para a aprendizagem. Tendo presente que a construção do conhecimento é feita por meio da imersão do sujeito, urge criar mecanismos para que esta seja uma característica essencial da didática escolar.

Ademais, o paradigma da afrocentricidade numa educação intercultural crítica, alinhada à ecologia de saberes e à descolonização epistemológica, considera que a experiência local importa, o espiritual é relevante para o desenvolvimento humano, a intuição está entrelaçada ao conhecimento. A educação não se importa apenas com o que é material, mas com todos os âmbitos da existência humana, sendo que o conhecimento estudado e produzido tem de servir à libertação humana. 


\section{CONSIDERAÇÕES TRANSITÓRIAS}

As diferenças culturais interpelam a educação escolar brasileira, tanto pela entrada de sujeitos diversos, quanto pelas pressões de movimentos existentes na sociedade. Este tem sido um desafio central para a escola contemporânea, fundamentada num paradigma científico ocidental. Construída junto à colonialidade do poder, a racionalidade moderna ocidental, torna-se excludente, na medida em que classifica culturas e epistemologias não ocidentais como hierarquicamente inferiores.

Como resultado, a escolarização atual é essencialmente excludente por aliar-se à lógica da colonialidade do poder. A interculturalidade crítica tem se atentado a esta questão, propondo a construção de relações pedagógicas basilarmente abertas às diferenças culturais e epistemológicas, a fim de promover a reinvenção radical da escola. Neste sentido, por meio da pesquisa teórica, desenvolvida no presente trabalho, apontamos o paradigma da afrocentricidade como uma das possibilidades de abertura epistemológica que ajude a refundar a educação, para que a diferença seja sua dimensão constitutiva e não aditiva. Ao refletir sobre possíveis reverberações do pensamento afrocentrado na educação, ensaiamos a tentativa de repensar a escolarização atual com base em referenciais subalternizados.

É urgente reinventar a educação escolar hegemônica. Temos uma escola fundada na exclusão, na oposição, projetada para dividir o mundo em certo ou errado, maus ou bons, cultos ou incultos, nós ou os outros - é a lógica do "ou", uma oposição basilar. Fundamentalmente a escolarização contemporânea é ainda um produto da dominação ocidental globalizada. A desconsideração das diferenças culturais, portanto, não é um problema de superfície, mas de fundamentos da educação que se reverberam em desrespeito ao diferente, em práticas pedagógicas dissociadas do universo cultural dos alunos e no objetivo de modelar todos de acordo com um ideal de homem ocidental.

Precisamos de outra escola, de outra educação, que se baseie na diferença, que seja atravessada pelas diferenças culturais nos fundamentos 
epistemológicos, nos conteúdos curriculares, nas práticas didáticopedagógicas, nos materiais escolares, nas linguagens e tecnologias utilizadas, nos espaços arquitetônicos, nas organizações do tempo, nas relações com a comunidade. Precisamos interculturalizar a escola em suas diversas dimensões e é nesta direção que o paradigma da afrocentricidade mostra-se potente, podendo ser ainda mais discutido.

Atentos ao caráter ainda tímido das considerações realizadas, compreendemos que incorporar uma perspectiva afrocentrada na educação, não é um reducionismo à problemática da afro descendência na escola, sequer é ignorar as contribuições ocidentais. Para além disto, considerar referenciais de pensamento africano é um processo de abertura intercultural, de descolonização epistemológica, de contrariedade à colonialidade do poder por meio da criação de espaços de legitimidade para um lugar de fala, concebido como inferior pelo Ocidente. Em uma sociedade fragmentada e caracterizada pelo intenso hibridismo, a afrocentricidade emerge não como uma proposta essencialista, mas na direção de um agir político de abertura paradigmática possibilitado por um fechamento transitório, no que se refere à identidade coletiva sensivel à dominação da hegemonia eurocêntrica.

O exercício empreendido neste texto revela que, incorporar bases epistemológicas subalternizadas na discussão educacional pode proporcionar outras formas de perceber e se relacionar com as diferenças culturais presentes na escola. Afinal, se o caráter excludente do sistema educacional atual é resultante de um paradigma pretensamente superior, que impõe hierarquias culturais sobre o mundo, urge revelar outras possibilidades paradigmáticas que sejam abertas às diferenças a fim de possibilitar que a educação conceba as diferenças culturais como riqueza constituinte de processos educativos, fundamentalmente interculturalizados.

Neste sentido, falar sobre afrocentricidade não é confinamento, mas um dos possíveis caminhos de proposição à abertura para variadas outras perspectivas epistemológicas na educação. Afinal, o pensamento afrocêntrico não se pretende universal como o paradigma racionalista da 
modernidade ocidental. Opostamente, a afrocentricidade declara-se como abertura epistêmica e cultural radical e, como apontamos, é referencial potente para fortalecer a construção de uma educação intercultural preocupada com a reinvenção escolar.

Investigações mais aprofundadas sobre 0 paradigma da afrocentricidade - e de outras posições epistemológicas dos subalternos, como a filosofia ubuntu (SANT'ANA, 2015) - podem auxiliar na formulação de políticas públicas, na ênfase à educação para as relações étnico-raciais e na proposição de currículos para a educação básica e superior, especialmente, para a formação docente, na qual são praticamente inexistentes reflexões sobre a educação a partir de referenciais de pensamento africano como a afrocentricidade.

\section{REFERÊNCIAS}

ASANTE, M. K. Afrocentricidade: notas sobre uma posição disciplinar. In: NASCIMENTO, E. L. (org.). Afrocentricidade: uma abordagem epistemológica inovadora. São Paulo: Selo Negro, 2009. p. 93-110.

BONIN, I. T.; RIPOLL, D.; GUIZZO, B. S. Para pensar a educação e as diferenças sob um enfoque cultural. Em Aberto, vol. 29, n 95, p. 25-37, jan./abr., 2016.

BORTONI-RICARDO, S. M. O professor pesquisador: introdução à pesquisa qualitativa. São Paulo: Parábola, 2008.

CANÁRIO, R. A escola: das "promessas" às "incertezas". Educação Unisinos, vol. 12, n² 2, mai./ago. 2008.

CANDAU, V. M. Cotidiano escolar e cultura (s). In: CANDAU, V. M. (org.).

Reinventar a escola. 7. ed. Petrópolis, RJ: Vozes, 2010.

CANDAU, V. M. Diferenças culturais, cotidiano escolar e práticas pedagógicas. In: CANDAU, V. M. (org.). Didática crítica intercultural: aproximações. Petrópolis, RJ: Vozes, 2012.

CANDAU, V. M. Educação intercultural: entre afirmações e desafios. In: MOREIRA, A. F.; CANDAU, V. M. Currículos, disciplinas escolares e culturas. Petrópolis, RJ: Vozes, 2014.

CANDAU, V. M. Apresentação. In: CANDAU, V. M. (org.). Interculturalizar, descolonizar, democratizar: uma educação 'outra'? Rio de Janeiro: 7 Letras, 2016. 
CANEN, A. Universos culturais e representações docentes: subsídios para a formação de professores para a diversidade cultural. Revista Brasileira de Educação, n 77, dez., 2001.

DEMO, P. Introdução à metodologia da ciência. 2. ed. São Paulo: Atlas, 1985.

FINCH III, C. S. A afrocentricidade e seus críticos. In: NASCIMENTO, E. L. (org.). Afrocentricidade: uma abordagem epistemológica inovadora. São Paulo: Selo Negro, 2009b. p. 167-180.

FINCH III, C. S.. Cheik Anta Diop confirmado. In: NASCIMENTO, E. L. (org.). Afrocentricidade: uma abordagem epistemológica inovadora. São Paulo: Selo Negro, 2009a. p. 71-92.

FINCH III, C. S.; NASCIMENTO, E. L. Abordagem afrocentrada, história e evolução. In: NASCIMENTO, E. L. (org.). Afrocentricidade: uma abordagem epistemológica inovadora. São Paulo: Selo Negro, 2009. p. 37-70.

FLEURI, R. M. Intercultura e educação. Revista Brasileira de Educação, n 23, mai./jun./jul./ago., 2003.

FLEURI, R. M. Políticas da diferença: para além dos estereótipos na prática educacional. Educação e Sociedade, vol. 27, n 95, mai./ago., 2006.

GROSFOGUEL, R. Para descolonizar os estudos de economia política e os estudos pós-coloniais: transmodernidade, pensamento de fronteira e colonialidade global. In: SANTOS, B. S.; MENESES, M. P. (orgs.). Epistemologias do sul. Coimbra: Almedina, 2009. p. 383-418.

MAZAMA, A. A afrocentricidade como um novo paradigma. In:

NASCIMENTO, E. L. (org.). Afrocentricidade: uma abordagem epistemológica inovadora. São Paulo: Selo Negro, 2009. p. 111-128.

MORAES, M. C. O paradigma educacional emergente. 16. ed. Campinas, SP: Papirus, 2012.

MOREIRA, A. F.; SILVA JUNIOR, P. M. Currículo, transgressão e diálogo: quando outras possibilidades se tornam necessárias. Revista Tempos e Espaços em Educação, vol. 9, n 18, p. 45-54, jan./abr., 2016.

MORIN, E. A via para o futuro da humanidade. Trad. Edgard de Assis Carvalho e Mariza Perassi Bosco. 2. ed. Rio de Janeiro: Bertrand Brasil, 2015.

NOGUERA, R. Afrocentricidade e educação: os princípios gerais para um currículo afrocentrado. Revista África e Africanidades, ano 3, n 11, nov. 2010.

OLIVEIRA, R. J.; CANEN, A.; FRANCO, M. Ética, multiculturalismo e educação: articulação possível? Revista Brasileira de Educação, $n^{\circ} 13$, jan./fev./mar./abr., 2000. 
QUIJANO, A. Colonialidad y modernidade/racionalidade. Perú Indígena, vol. 13, n² 29, p. 11-20, 1992.

RABAKA, R. Teoria crítica africana. In: NASCIMENTO, E. L. (org.).

Afrocentricidade: uma abordagem epistemológica inovadora. São Paulo: Selo Negro, 2009. p. 129-146.

SANT'ANA, J. V. B. Descolonização, reinvenção escolar e filosofia africana ubuntu: uma relação possível. Revista Três Pontos, vol. 12, nº 1, jan./jun., 2015.

SANT'ANA, J. V. B.; LOPES, C. R. Educação brasileira e diversidade étnicoracial: a escola, a exclusão do negro e a necessidade de reinvenção escolar. Revelli, vol. 7, n² 2, dezembro, 2015.

SANTOS, B. S. Para além do pensamento abissal: das linhas globais a uma ecologia de saberes. In: SANTOS, B. S.; MENESES, M. P. (orgs.). Epistemologias do sul. Coimbra: Almedina, 2009. p. 23-72.

SANTOS, B. S. Uma concepção multicultural de direitos humanos. Lua Nova, Unicamp, n³9, 1997.

SILVA, G. F. Multiculturalismo e educação intercultural: vertentes históricas e repercussões atuais na educação. In: FLEURI, R. M. (org.). Educação

intercultural: mediações necessárias. Rio de Janeiro: DP\&A, 2003. p. 17-52.

SODRÉ, M. Reinventando a educação: diversidade, descolonização e redes. 2. ed. Petrópolis, RJ: Vozes, 2012.

VILAÇA, M. L. C. Pesquisa e ensino: considerações e reflexões. E-scrita, vol. 1, $\mathrm{n}^{\circ} 2$, mai./ago., 2010.

WALSH, C. Interculturalidad y colonialidad del poder. Un posicionamento "otro" desde la diferencia colonial. In: CASTRO-GÓMEZ, S.; GROSFOGUEL, R. El giro decolonial: reflexiones para una diversidad epistémica más allá del capitalismo global. Bogotá: Instituto Pensar, 2007.

WALSH, C. Interculturalidad crítica y educación intercultural. In: VIAÑA, J.; TAPIA, L. WALSH, C. (orgs.). Construyendo interculturalidad crítica. La Paz, Bolívia: Instituto Internacional de Integración, 2010.

Recebido em: 02 de janeiro de 2018 Aprovado: 31 de agosto de 2018 